\title{
Dossiê
}

\section{CURSO DE PEDAGOGIA NO BRASIL: TENSÕES, CONTROVÉRSIAS E PERSPECTIVAS}

\author{
Pedagogy course in Brazil: tensions, controversies and perspectives \\ Curso de pedagogia en Brasil: tensiones, controversias y perspectivas
}

Andréia Nunes Militão*

Shirleide Pereira da Silva Cruz**

https://doi.org/10.38117/2675-181X.formov2021.v3i1n5.17-28.

\section{Resumo}

O curso de Pedagogia no Brasil tem uma trajetória marcada por disputas de diferentes projetos formativos, notadamente pela contenda em torno da identidade e da organização do curso, expressa na formação que oferece, no campo de atuação desse profissional e no lócus dessa formação. As vigentes Diretrizes Nacionais Curriculares para o Curso de Pedagogia, de 2006, sistematizaram a docência como identidade e princípio norteador, agregada à possibilidade de construção e requerimento de conhecimentos pedagógicos em diferentes modalidades e espaços educativos tendo a gestão e a pesquisa como elementos constituintes. Contudo, a Resolução n. ${ }^{\circ}$ 02/2019 abriu caminho para a fragmentação do curso de Pedagogia, além de segmentar a gestão da docência e silenciar sobre a pesquisa como princípio formativo. Este dossiê visa reunir estudos de pesquisadores que possuem um acúmulo histórico e investigativo sobre a Pedagogia como campo de conhecimento e como campo profissional e seus diferentes mecanismos de regulação, com vistas a analisar criticamente a proposta apontada pela Resolução n. ${ }^{\circ}$ 2/2019 desvelando, assim, suas controvérsias, tensões e perspectivas. A questão que percorre o presente Dossiê, composto por 14 artigos, de autores de diversas instituições brasileiras, portanto, é: Quais são as implicações da Resolução CNE/CP n. ${ }^{\circ}$ 2/2019 para o curso de Pedagogia?

Palavras-chave: Curso de Pedagogia; Formação de professores; Diretrizes Curriculares. 


\begin{abstract}
The Pedagogy course in Brazil has a trajectory marked by disputes of different formative projects, nodded by the contention around the identity and organization of the course, expressed in the training it offers, in the field of action of this professional and in the locus of this training. The current National Curriculum Guidelines for the Pedagogy Course, 2006, systematized teaching as identity and guiding principle, added to the possibility of construction and application of pedagogical knowledge in different modalities and educational spaces with management and research as constituent elements. However, Resolution no. 02/2019 paved the way for the fragmentation of the Pedagogy course, in addition to segmenting teaching management and silencing research as a formative principle. This dossier aims to gather studies of researchers who have a historical and investigative accumulation on Pedagogy as a field of knowledge and as a professional field and its different regulatory mechanisms, with a view to critically analyzing the proposal pointed out by Resolution no. 2/2019 thus unto recalling its controversies, tensions and perspectives. The question that goes through this Dossier, composed of 14 articles of authors from various Brazilian institutions, therefore, is: What are the implications of CNE/CP Resolution no. 2/2019 for the Pedagogy course?
\end{abstract}

Keywords: Pedagogy Course; Teacher education; Curricular guidelines.

\title{
Resumen
}

El curso de Pedagogía en Brasil tiene una trayectoria marcada por disputas de diferentes proyectos formativos, asentidos por la contención en torno a la identidad y organización del curso, expresada en la formación que ofrece, en el campo de acción de este profesional y en el lugar de esta formación. Los actuales Lineamientos Curriculares Nacionales para el Curso de Pedagogía, 2006, sistematizaron la enseñanza como identidad y principio rector, sumó a la posibilidad de construcción y aplicación de conocimientos pedagógicos en diferentes modalidades y espacios educativos con la gestión y la investigación como elementos constitutivos. Sin embargo, la Resolución No 2/2019 allanó el camino para la fragmentación del curso de Pedagogía, además de segmentar la gestión docente y silenciar la investigación como principio formativo. Este dossier tiene como objetivo reunir estudios de investigadores que tienen una acumulación histórica e investigativa sobre la Pedagogía como campo de conocimiento y como campo profesional y sus diferentes mecanismos normativos, con miras a analizar críticamente la propuesta señalada por la Resolución No 02/2019 para así recordar sus controversias, tensiones y perspectivas. La pregunta que recorre este Dossier, compuesto por 14 artículos, de autores de diversas instituciones brasileñas, por lo tanto, es: ¿Cuáles son las implicaciones de la Resolución CNE/CP N²/2019 para el curso de Pedagogía?

Palabras clave: Curso de Pedagogía; Formación de profesores; Lineamientos curriculares.

Formação em Movimento v.3, i.1, n.5, p. 17-28, jan./jun. 2021. 
Historicamente, o curso de Pedagogia no Brasil, tem uma trajetória marcada por disputas de diferentes projetos formativos, notadamente pela contenda em torno da identidade e da organização do curso, expressa na formação que oferece, no campo de atuação desse profissional e no lócus dessa formação.

Após um longo período de debates, controvérsias legais e discussões epistemológicas, as vigentes Diretrizes Nacionais Curriculares para o Curso de Pedagogia de 2006, sistematizaram a docência como identidade e princípio norteador, conforme consensuado pelo movimento dos educadores, agregada à possibilidade de construção e requerimento de conhecimentos pedagógicos em diferentes modalidades e espaços educativos tendo a gestão e a pesquisa como elementos constituintes.

As atuais Diretrizes Nacionais para a Formação Inicial de Professores da Educação Básica e Base Nacional Comum para a Formação Inicial, instituídas pela Resolução CNE/CP n. ${ }^{\circ}$ 2/2019, contudo, abriram caminho para a fragmentação do curso de Pedagogia, além de segmentar a gestão da docência e silenciar sobre a pesquisa como princípio formativo.

Desta feita, o Dossiê Curso de Pedagogia no Brasil: tensões, controvérsias e perspectivas, que integra este número da revista Formação em Movimento, tem como objetivo precípuo reunir estudos de pesquisadores que possuem um acúmulo histórico e investigativo sobre a Pedagogia como campo de conhecimento e como campo profissional e seus diferentes mecanismos de regulação, com vistas a analisar criticamente a proposta apontada pela Resolução CNE/CP n. ${ }^{\circ}$ 2/2019 desvelando, assim, suas controvérsias, tensões e perspectivas.

O presente Dossiê é perpassado pelo questionamento sobre quais são as implicações da Resolução CNE/CP n. ${ }^{\circ}$ 2/2019 para o curso de Pedagogia? Consideramos que esta legislação se apresenta como um retrocesso, ao mesmo tempo em que se alinha à constituição de uma hegemonia cultural, integrando diversas frentes de atuação principalmente tendo as políticas públicas como mediação dos princípios neoliberalizantes na gestão pública e que têm atacado de frente a educação enquanto direito social e, por conseguinte, a formação de professores e professoras de nosso país. E para entendermos as implicações que se direcionam para o curso de Pedagogia, esse Dossiê é organizado, em três eixos temáticos, em torno das tensões, das controvérsias e das perspectivas.

Formação em Movimento v.3, i.1, n.5, p. 17-28, jan./jun. 2021. 
Tensões porque historicamente o curso de Pedagogia no Brasil tem uma trajetória marcada por disputas de diferentes projetos formativos. Em sua gênese, quando da criação, em 1939, o curso foi submetido a uma inversão de ações que o validaria. Propôs, naquele momento, a formação de um especialista/técnico para atuar no recém-criado Ministério da Educação e Saúde, estabelecendo um campo de atuação restrito desse profissional. Assim, se desconsiderou uma abrangente necessidade frente ao complexo fenômeno educacional formal que vinha sendo estruturado do Brasil, desde o processo de institucionalização da escola, iniciado no final do século XIX e ampliado pelas propostas problematizadoras do então iniciado século XX, em pleno movimento de mudanças econômicas, sociais, políticas e culturais pelo advento da República. E mais, não considerou, também, as diferentes reinvindicações do movimento de educadores, de modo particular, e da sociedade brasileira como um todo, acerca da formação do magistério.

O modelo formativo instituído para o curso de Pedagogia, nesse período inicial foi norteado pelo chamado esquema $3+1$ que, em seu bojo, traz a cisão entre fundamentação teórica e conhecimento prático, sob o ranço da divisão entre trabalho manual e trabalho intelectual. Constituía-se, assim, dois formatos de curso, um de bacharelado, que habilitava o técnico em educação, e outro de licenciatura, habilitando o pedagogo(a) para lecionar nos então cursos normais, destinados à formação de professores primários, vigentes naquela época.

Controvérsias ainda devido a uma série de legislações posteriores que foram implementadas em torno do debate de organização do curso, que perduram até na atualidade, e que dão vazão ao retorno de temas que pareciam já terem sido vencidos. Entretanto, devido a diferentes correlações de força, tais temas veem à tona causando, por vezes, dispêndio de ações políticas e de pesquisa que poderiam ser canalizadas para o aprofundamento, por exemplo, da clareza epistemológica da pedagogia enquanto conhecimento científico. Assim, se retomam, por exemplo, as proposições de manutenção, por dentro do curso, das habilitações profissionais, instituídas nos anos 1970 e que só serão extintas no início do século XXI. Sua extinção incorporou um rico debate no seio das instituições formadoras desde o período de redemocratização nos anos de 1990, problematizando a divisão social imposta num âmbito operacional de alocação e fragmentação de postos de trabalho, referentes à organização do trabalho pedagógico na escola..

Contudo, nesse espaço temporal, ainda fomos tomados de assalto pelo Decreto n. ${ }^{\circ}$ 3276/1999 que intentou retirar do espaço universitário a formação em Pedagogia, praticamente pretendendo extingui-lo. Tal proposta era uma tentativa de contraposição ao processo de construção dos projetos de cursos, espalhados pelas universidades 
brasileiras, que acompanhavam as reflexões de consolidação da identidade docente nos cursos de Pedagogia. Tal processo despontava como um horizonte profícuo para se repensar a formação de professores capitaneadas pelo intenso movimento de educadores, representado marcadamente pela, então recém-constituída, CONARFECE, que, posteriormente, se tornou nossa estimada Associação Nacional pela Formação dos Profissionais de Educação - ANFOPE.

Os marcos históricos comparecem na maioria do conjunto dos textos que compõem o Dossiê, que nos brindam com análises documentais detalhadas, questões de pesquisa problematizadoras das tensões e controvérsias que tem marcado a historicidade do curso. Essa historicidade emerge como categoria ontológica, que não olha apenas para o passado de modo estático e imprime apenas uma lógica descritiva, mas, que desenvolve um olhar diacrônico pautado por questões prementes do presente e que assim alimentam e retroalimentam perspectivas, sendo estas, principalmente, de resistências e afirmação de princípios formativos para constituição de uma qualidade socialmente referenciada para o curso de Pedagogia.

Dando continuidade a esse olhar histórico-político, em termos de políticas educacionais e, por conseguinte, políticas curriculares para os cursos de formação de professores, dentre eles o curso de pedagogia, temos o que Brzezinski (2011) aponta como uma "identidade consensuada". Para Brzezinski (2011, p. 128) essa identidade para o curso de Pedagogia é resultante de uma [...] "negociação possível entre conflitos instalados na arena política, em que eclodiam choques de temporalidade e de concepções de mundo, de sociedade, de formação, de docência, de pedagogo", mediante, a promulgação das Diretrizes Nacionais Curriculares para o Curso de Pedagogia de 2006. Essas Diretrizes, ainda atuais e vigentes, sistematizam a docência como identidade e princípio norteador agregada à possibilidade de construção e requerimento de conhecimentos pedagógicos em diferentes modalidades e espaços educativos tendo a gestão e a pesquisa como elementos constituintes.

Também temos estudos que se somam ao dossiê exatamente desvelando limites e possibilidades dessas diretrizes, indicando que estas podem ser, principalmente, um instrumento de luta para se consolidar princípios e se contrapor aos projetos de organização dos cursos de pedagogia e de formação de professores nas demais áreas de atuação na educação básica sob a égide do aligeiramento, fragmentação e divisão do trabalho docente tal como fora comentado anteriormente.

As atuais e vigentes Diretrizes Nacionais Curriculares para o Curso de Pedagogia, de 2006, ganham um reforço na defesa de uma clara definição de docência enquanto identidade para a formação de professores e que endossa a tríade ensino-pesquisa-gestão

Formação em Movimento v.3, i.1, n.5, p. 17-28, jan./jun. 2021. 
como dimensões integradas e integradoras da formação e atuação de professoras e professoras no seio das escolas e das redes de ensino. Esse reforço foi dado, exatamente, pela Resolução CNE/CP n. ${ }^{\circ}$ 2/2015, que, segundo Dourado e Tuttman (2019, p. 202), buscou subsidiar uma maior organicidade das políticas de formação de professores no Brasil por meio da elaboração de marcos para a formação inicial e continuada articulando “[...] políticas e gestão para a educação básica e a educação superior e para as políticas direcionadas à valorização dos profissionais da educação [...] articulação entre as instituições de educação superior e de educação básica,[...]” que contemplem, portanto:

Sólida formação teórica e interdisciplinar dos profissionais; A inserção dos estudantes de licenciatura nas instituições de educação básica da rede pública de ensino, espaço privilegiado da práxis docente; $\mathrm{O}$ contexto educacional da região onde será desenvolvido; Atividades de socialização e avaliação dos impactos; Aspectos relacionados à ampliação e ao aperfeiçoamento do uso da língua portuguesa e à capacidade comunicativa, oral e escrita, como elementos fundamentais da formação dos professores e à aprendizagem de Libras; Questões socioambientais, éticas, estéticas e relativas à diversidade étnicoracial, de gênero, sexual, religiosa, de faixa; geracional e sociocultural como princípios de equidade (DOURADO; TUTTMAN, 2019, p. 202)

Assim, alguns dos textos do dossiê debruçam-se sobre as experiências de construção de projetos pedagógicos de cursos, à luz portanto, das possibilidades que estas duas diretrizes favoreciam, desenvolvendo análises críticas sobre a Resolução CNE/CP n. $2 / 2019$, que define as Diretrizes Curriculares Nacionais para a Formação de professores para a Educação Básica e institui a Base Nacional Comum para a Formação Inicial de Professores da Educação Básica (BNC-Formação).

Desta feita, o eixo das perspectivas também presente no título do Dossiê endossa a ideia de uma resistência propositiva marcada, portanto, pela sistematização de ideias e fundamentos, muitos deles já materializados em propostas construídas coletivamente e, também, descritos no conjunto dos textos deste Dossiê. Assim, esses textos denotam a construção da "alegria do processo", tal como nos chama Paulo Freire em seu livro Pedagogia da Autonomia (1996, p. 53), indicando a possibilidade, de unir o rigor metódico e político de resistir somado a alegria de aprendermos juntos. É o que fazemos, junto(a)s, no coletivo dos autores e autoras que contribuíram para a elaboração deste Dossiê, mesmo que, historicamente, estejamos imersos numa crise sanitária da Pandemia da COVID-19, e atacados por uma política antidemocrática e aniquiladora de direitos sociais, conquistados a duras penas. Assim, nos propomos a aprendermos junto(a)s com os relatos sobre o curso de Pedagogia ora elencados.

Formação em Movimento v.3, i.1, n.5, p. 17-28, jan./jun. 2021. 
O presente Dossiê, composto por 15 artigos tematiza, portanto, as tensões, as controvérsias e as perspectivas atuais para o curso de Pedagogia. $\mathrm{O}$ artigo Curso de Pedagogia em questão: de volta para o passado? de autoria de Leda Scheibe e Zenilde Durli abre o dossiê. As autoras desvelam as possíveis implicações das atuais políticas de formação de professores sobre o curso de Pedagogia, notadamente, denunciam a proposta preliminar de reformulação das Diretrizes Curriculares Nacionais para o Curso de Pedagogia (2006), apresentada no formato de slides, por retomar as habilitações (bacharelado e licenciatura) em detrimento de uma Pedagogia Plena, além de impor uma Licenciatura Multidisciplinar em Educação Infantil e uma Licenciatura Multidisciplinar em Ensino Fundamental.

Na sequência, o artigo de Andressa Graziele Brandt, Márcia de Souza Hobold e Isabel Maria Sabino de Farias, Curso de Pedagogia em cenário de (contra)reforma: concepções de formação de professores em disputa, apresenta uma análise das concepções de formação de professores contidas na Resolução CNE/CP n. ${ }^{\circ}$ 1/2006 e na Resolução CNE/CP n. ${ }^{\circ}$ 2/2019. As autoras conclamam os leitores a defender, no campo de formação de professores, os docentes como intelectuais orgânicos, condição negada pela Resolução CNE/CP 2/2019.

A reflexão de Yuna Lélis Beleza Lopes e Noeli Prestes Padilha Rivas intitulada Base comum nacional ou base nacional comum para a formação inicial de professores da educação básica: a quem interessa a inversão da nomenclatura? provoca-nos a discutir as implicações do cenário político atual para as políticas de formação docente. As autoras asseveram que os novos marcos legais obliteram tanto a produção do campo da formação de professores como a atuação das entidades acadêmico-científicas, especialmente da Anfope, na defesa de uma formação crítica e científica.

De autoria de Ângela Maria Silveira Portelinha, Berenice Lurdes Borssoi e Vanice Schossler Sbardelotto, o texto intitulado Diretrizes Curriculares Nacionais $n .^{\circ} 2$ de 2019: a possivel dissolução, revela as dificuldades impostas para à formação em Pedagogia advindas da aprovação, em 2019, das Diretrizes Curriculares Nacionais de Formação Inicial de Professores. Para além da fragmentação do curso, as autoras denunciam a concepção que transforma o professor em tarefeiro, contido nestas DCNs, a partir da imposição de competências e habilidades de viés cognitivo, psicofísico e emocional e reafirmam a defesa do curso de Pedagogia ancorado na articulação da docência, pesquisa e gestão no processo formativo.

A seguir, Kátia Augusta Curado Pinheiro Cordeiro da Silva, por meio do artigo $A$ pedagogia plena: uma proposta unitária de formação assevera que a formação de sujeitos capazes de analisar, compreender e lidar com as mudanças da e na vida social e suas

Formação em Movimento v.3, i.1, n.5, p. 17-28, jan./jun. 2021. 
implicações no sistema educacional, na escola e/ou fora deve ocorrer em um curso de pedagogia plena. A autora define esse curso como "um curso de graduação plena com projeto pedagógico próprio, referenciado na Base Comum Nacional e destinado à formação de professores" e a formação de "profissionais para as atividades de apoio escolar; organização e gestão educacionais; e produção e difusão do conhecimento científico e tecnológico do campo educacional", destacando seu comprometimento "com a educação crítica de bases teóricas sólidas e voltada para a formação humana omnilateral, emancipadora".

O artigo de Antonia Alves Pereira Silva, Um passo à frente e dois atrás: reflexões sobre a constituição da práxis no curso de Pedagogia, visa compreender a formação do pedagogo a partir da epistemologia da práxis, enquanto princípio epistemológico formativo, localizado nas Resoluções CNE/CP n. ${ }^{\circ}$ 1/2006 e CNE/CP n. ${ }^{\circ}$ 2/2015. Em sentido oposto, a Resolução CNE/CP n. ${ }^{\circ}$ 2/2019 propõe um projeto de formação de professores/as ancorado em competências e habilidades princípio epistemológico formativo.

No artigo Curso de pedagogia no Brasil: algumas discussões sobre as políticas de formação os autores, Maria Eneida da Silva, Andréa Kochhann e Miro Almeida, exploram as Diretrizes e Base Nacional Comum para a Formação Inicial de Professores da Educação Básica consubstanciadas pela Resolução CNE/CP n. ${ }^{\circ}$ 2/2019, cuja proposta transforma a "formação docente num instrumento pragmático utilitarista e a fragmenta uma vez que desconsidera as idiossincrasias da diversidade brasileira, padronizando a formação inicial do professor pedagogo". A partir da perspectiva crítica e emancipatória, os autores apontam que a política neoliberal conservadora induz a concepção de educação pautada na eficiência do capital e, com anuência do CNE e MEC, promove ataques tanto na formação inicial dos futuros profissionais da educação básica e do pedagogo de nível superior. Em perspectiva contrária, defendem a valorização da unidade teoria e prática que fundamenta tanto a didática quanto os valores inerentes ao exercício pleno da docência do pedagogo no país.

$\mathrm{O}$ artigo intitulado Extensão universitária e a formação de professores no curso de Pedagogia: (dis) posições para além das competências, de Roberta Pereira de Paula Rodrigues e Giseli Barreto da Cruz, centra a análise em ações de extensão universitária desenvolvidas por estudantes de um curso de Pedagogia. Para as autoras, a extensão universitária configura componente curricular estratégico para a afirmação de práticas comprometidas com a superação de uma formação para e pelas competências, elemento contido na Resolução CNE/CP n. ${ }^{\circ}$ 2/2019 e Resolução CNE/CP n. ${ }^{\circ}$ 1/2020. Asseveram as autoras que a Extensão Universitária pode representar "um caminho para a superação

Formação em Movimento v.3, i.1, n.5, p. 17-28, jan./jun. 2021. 
de uma cultura curricular instrumental e utilitária, tal qual vem sendo proposta pelas novas Diretrizes presentes na Resolução CNE/CP n. ' 2/2019”.

Franciele Aparecida Carneiro Stefanello, Susana Soares Tozetto e Priscila da Luz Kailer tematizam no texto, A gestão escolar nos cursos de pedagogia das universidades públicas do Paraná, a formação do gestor com base nos Projetos Político Pedagógicos. As autoras apontam para a necessidade de se instituir padrões curriculares que assegurem a complexa formação do gestor, pois com supressão, nos cursos de Pedagogia, das habilitações de supervisão escolar, administração e orientação do currículo, deu-se origem a um grande leque de possibilidades de atuação. Conquanto, os currículos das instituições de ensino superior sejam bastante heterogêneos, os cursos de pedagogia das IES públicas do Paraná, têm carga horária destinada para formação do gestor, pois, envolvem amplas discussões sobre políticas educacionais, estrutura do sistema de ensino, avaliação, gestão democrática, e uma carga horária destinada para os estágios.

As reflexões de Ronaldo Figueiredo Venas, Rejane de Oliveira Alves e Leila da Franca Soares deram relevo para o artigo O antagonismo da Resolução CNE/CP 2/2019: reflexões sobre a atualização curricular do curso de Pedagogia da FACED/UFBA com base na Resolução $C N E / C P n{ }^{\circ}$ 2/2015. Nele, são problematizados o processo de atualização curricular da formação em Pedagogia da FACED/UFBA com base na Resolução CNE/CP n. ${ }^{\circ}$ 2/2015 e as implicações da Resolução CNE/CP n. ${ }^{\circ}$ 02/2019 para a formação de professores/as no curso de Pedagogia. Venas, Alves e Soares advogam a favor da Resolução CNE/CP n. ${ }^{\circ}$ 2/2015 por entenderem que este normativo aponta para uma formação inicial de qualidade aportada nas diferenças "considerando as diferenças de ritmos e formas de aprendizagem decorrentes ou não de deficiência, natureza ambiental-ecológica, étnico-raciais, de gêneros e sexualidades, faixas geracionais, classes sociais, religiões, necessidades educacionais especiais, entre outras". Concluem os autores, essas temáticas não comparecem na Resolução CNE/CP n. ${ }^{\circ}$ 2/2019 "porque não interessa aquilo que é diverso, mas tão somente a manutenção de uma hierarquia, de uma ordem, de um alinhamento ao conservadorismo e tradicionalismo".

O Curso de Pedagogia da UFAC: 50 anos de enfrentamento e resistência na defesa da formação de professores intitula o texto de Adriana R. dos Santos, Mark Clark A. de Carvalho e Tatiane Castro dos Santos, que versa sobre a trajetória do Curso de Pedagogia da Universidade Federal do Acre até a sua configuração, no tempo presente, ancorada na Resolução CNE/CP n. ${ }^{\circ}$ 1/2006 e na Resolução CNE/CP n. ${ }^{\circ}$ 2/2015. Perspectiva, ainda, as possíveis implicações da Resolução CNE/CP n. ${ }^{\circ}$ 2/2019 para o curso analisado, notadamente, por "desconsiderar o processo de construção coletiva

Formação em Movimento v.3, i.1, n.5, p. 17-28, jan./jun. 2021. 
empreendido pelo movimento nacional, a autonomia das agências de formação e a definição de um projeto institucional de formação de professores".

De autoria de Adriana Varani e de Dirce Zan, o artigo Reflexões da política de formação inicial a partir de dados de egressas do curso de pedagogia da UNICAMP discute as orientações para a formação de professores em âmbito nacional e estadual, nomeadamente, a Deliberação do CEE/SP n. ${ }^{\circ}$ 154/2017 e a Resolução CNE/CP n. ${ }^{\circ}$ 02/2019, normativos calcados na racionalidade técnica. As autoras desconstroem o argumento, disseminado por diversos gestores da educação paulista, que centra como principal crítica nos processos formativos, ofertados pelas universidades públicas, ser muito teórico. Adiciona-se às este discurso, a responsabilização dos professores pelo baixo desempenho educacional. Entre outros aspectos, Varani e Zan descontroem a narrativa com dados empíricos, baseados no próprio "número de profissionais egressos da universidade pública que se insere no quadro da educação escolar pública", já que este "não é suficiente para corroborar a lógica discursiva da culpabilização individual para a qualidade ou não de nosso sistema educacional".

O texto $O$ curso de Pedagogia em foco: a inserção dos egressos da UFOP no campo profissional, de autoria de Regina Magna Bonifácio de Araújo, Nilzilene Imaculada Lucindo e Iris Madalena Feijó Braga, também confere foco nos egressos do curso de Pedagogia da UFOP, entendendo a pesquisa e o acompanhamento dos egressos como estratégia primordial para avaliação do próprio curso. O estudo empreendido indica um nível de satisfação favorável por parte dos egressos com a formação, pois ela tem garantido a inserção na área educacional e de forma rápida.

O penúltimo texto, denominado A prática como componente curricular: traduções curriculares, proposto por Maria Roseli Gomes Brito de Sá problematiza os contextos de produção das políticas para a formação de professores no Brasil, discute as traduções curriculares e apresenta uma proposição para a Prática como Componente Curricular, entendendo-a como uma fusão entre teoria e prática, denominadas pela autora de teoriaprática. Na acepção de Sá, a Prática como Componente Curricular se constituiria em espaço de resistência à Resolução CNE n. ${ }^{\circ}$ 2/2019. A autora assevera que a "prática em sua potência formativa é, para nós, uma atitude política face ao desmonte das políticas comprometidas com uma educação de qualidade social”.

Fechando o Dossiê, temos o texto Curso de Pedagogia e a Formação de Professores/as em Educação Infantil: FAED/ICED/UFPA, elaborado por Ana Maria Orlandina Tancredi. O artigo enfoca o curso de Licenciatura Plena em Pedagogia da Universidade Federal do Pará (UFPA), recuperando historicamente a instalação do curso, em 1954, no estado do Pará. Explicita, entre outros aspectos, os embates travados, neste

Formação em Movimento v.3, i.1, n.5, p. 17-28, jan./jun. 2021. 
longo percurso, acerca da defesa da expansão universidade e da interiorização do curso. $\mathrm{O}$ processo de interiorização do curso foi, segundo a autora, opção para atender a crescente demanda social por uma formação de professores para exercer o magistério na Educação Infantil e nas séries iniciais do Ensino Fundamental, articulada à formação para a gestão, supervisão e à educação não formal. Finaliza questionando as implicações da Resolução CNE/CP n. ${ }^{\circ}$ 02/2019 a formação de professores/as para a Educação Infantil.

Ressalta-se, por fim, que a iniciativa deste Dossiê resulta da articulação entre a editoria da Revista Formação em Movimento e um grupo de pesquisadoras de universidades públicas que assumem a formação de professores/as como objeto de análise e de investigação em suas trajetórias profissionais, especialmente no âmbito dos grupos de pesquisa sob suas lideranças, a saber Márcia Hobold (UFSC/FOPPE), Isabel Sabino (UECE/EDUCAS), Magali Silvestre (UNIFESP/GEODDIP), Andréia Nunes Militão (UEMS-UFGD/GEPPEF) e Katia Curado e Shirleide Cruz (UnB/GEPFAPe).

Ao tematizarmos o Curso de Pedagogia no Brasil: tensões, controvérsias e perspectivas objetivamos apresentar no cenário atual, de forma plural e coletiva, subsídios teóricos, analíticos e políticos com vistas a alimentar o debate e as resistências ao processo de reforma da formação de professores, em curso. Encerramos este Dossiê em meio ao anúncio de duas boas notícias: a prorrogação do prazo para a implementação da Resolução CNE/CP n. 2/2019 e a extinção da Comissão de Revisão das Diretrizes Curriculares do Curso de Pedagogia de 2006.

\section{Referências}

BRZEZINSKI, Iria. Pedagogo: delineando identidade(s). Revista UFG, 2011, Ano XIII, n. 10, 2011.

DOURADO, Luiz F.; TUTTMAN, Malvina T. Dossiê - Formação do magistério da educação básica nas universidades brasileiras: institucionalização e materialização da Resolução 2/2015. Formação em Movimento, v.1, n.2, p. 197-217, jul./dez. 2019. Disponível em http://costalima.ufrrj.br/index.php/FORMOV/article/view/503/81 Acesso em 10 Agosto 2021.

FREIRE, Paulo. Pedagogia da Autonomia. 27ª ed. São Paulo: Paz e Terra, 1996.

SILVA, Carmen Sílvia B. da. Curso de Pedagogia no Brasil: história e identidade. Campinas, SP: Cortez, 2003.

Formação em Movimento v.3, i.1, n.5, p. 17-28, jan./jun. 2021. 
Curso de Pedagogia no Brasil: tensões, controvérsias e perspectivas

*Andréia Nunes Militão é Doutora em Educação (UNESP). Professora Adjunta da UEMS (Universidade Estadual de Mato Grosso do Sul) e docente vinculada ao Programa de PósGraduação em Educação da UFGD (Universidade Federal da Grande Dourados). É líder do GEPPEF (Grupo de Estudo e Pesquisa Políticas Educacionais e Formação de Professores). Atualmente é vice-presidente da Região Centro-Oeste da Anfope (Gestão 2021-2023) e na Anped participa ativamente do GT-8 (Formação de Professores), sendo parecerista ad hoc e ex-coordenadora do GT-8 na Região CO.

E-mail: andreiamilitao@uems.br

https://orcid.org/0000-0002-1494-8375.

** Shirleide Pereira da Silva Cruz é formada em Pedagoga, com Mestrado e Doutorado em Educação, pela UFPE. É professora adjunta da Faculdade de Educação, vinculada ao Programa de Pós-graduação em Educação da Universidade de Brasília (UNB), na Linha de Pesquisa: Profissão docente, currículo e avaliação. É pesquisadora do GEPFAPe - Grupo de Estudo e Pesquisa sobre atuação e formação do professor/Pedagogo (UnB) e integra como formadora o Centro de Estudos em Educação e Linguagem da UFPE.

E-mail: shirleidesc@gmail.com

https://orcid.org/0000-0002-4639-8400. 